\title{
Analysis of Dominant Factors for Density Current Sediment Discharge Efficiency of Xiaolangdi Reservoir
}

\author{
Siqi Jiang, Junhua Zhang, Guoming Gao, Huaibao Ma, Ting Wang \\ Yellow River Institute of Hydraulic Research, YRCC Zhengzhou, Henan, 450003, China, \\ jiangsiqi0505@126.com
}

\begin{abstract}
Keywords: Xiaolangdi Reservoir, Reservoir Operation, Retrogressive Erosion, Density Curren Abstract. This paper has analyzed impact on shaping density current forward of the Reservoir and sediment discharge of Sanmenxia Reservoir water storage capacity before flood season and discharge method, and pointed out that Sanmenxia Reservoir shall store water as much as possible before flood season and gradually enlarge water outflow before discharge in the process of regulation; on the basis of correlation between docking water level and delta vertex elevation, this paper has pointed out that Xiaolangdi Reservoir occurs retrogressive erosion and longitudinal erosion which can greatly increase silt concentration at plunging point of density current when docking water level is close to or is lower than the sedimentation delta vertex elevation of Xiaolangdi Reservoir and is combined with large flow discharging process of Sanmenxia Reservoir.
\end{abstract}

\section{Introduction}

Water and sediment regulation for shaping density current artificially before flood season of Yellow River is to make full use of water reserve upper water level limit of Wanjiazhai and Sanmenxia Reservoir, to erode siltation during non-flood season of Sanmenxia Reservoir and sediment deposition at the end of Xiaolangdi Reservoir through integrated regulation of Wanjiazhai, Sanmenxia and Xiaolangdi Reservoir under the condition of no flood in the middle stream, and accordingly to shape density current in Xiaolangdi Reservoir with sediment discharge out of the Reservoir, and finally to realize target of sediment discharge of Xiaolangdi Reservoir and siltation shape regulation at the end of the Reservoir (Fig. 1). To shape density current can change waste reservoir water into sediment discharge water and then make reservoir sediment discharge and siltation reservoir reduce, and finally make reservoir water flow into the sea with sediment outflow.

Based on integrated regulation of main stream reservoir, eight artificial density current shaping were made during water and sediment regulation period from 2004 to 2014, and sediment discharge was different from different water and sediment inflow, boundary condition and reservoir application method.

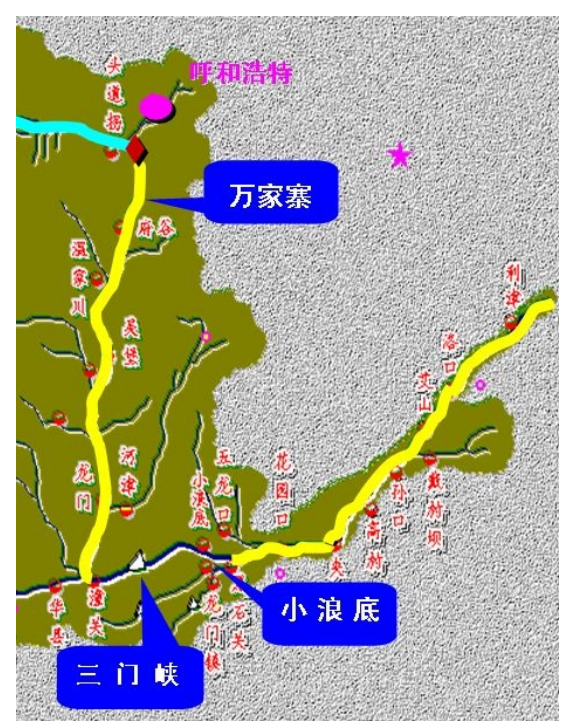

Fig. 1 Sketch Map of Reservoir Location

\section{Water and Sediment Regulation Process of Xiaolangdi Reservoir before Flood Season in a typical year}

In 2011 the water-sediment regulation during the storage capacity of 026 million $\mathrm{t}$, sand outbound sediment 037.8 million t, row of fly as high as $145.4 \%$, desilting high in 2011 as a typical year, the analysis of the xiaolangdi reservoir flood season the water-sediment regulation process.

During water and sediment regulation of 2011, sediment inflow of Xiaolangdi was 26 million tons and sediment outflow was 37.8 million tons. According to water and sediment process of Sanmenxia Reservoir, sediment regulation period of Xiaolangdi Reservoir can be divided into two stages with spread time into consideration, the first stage is to shape density current forward in delta 
vertex of Xiaolangdi Reservoir before sediment discharge of Sanmenxia Reservoir, and sediment outflow was 28.5 million tons in 2011 , which took up $75.4 \%$ total sediment discharge volume of Xiaolangdi Reservoir during water and sediment regulation period; the second stage only got 9.3 million tons sediment outflow of density current resulted from sediment discharge of Sanmenxia Reservoir and sediment discharge ratio of Xiaolangdi Reservoir was 35.8\% (Table 1).

Table 1. Water and Sediment Inflow and Outflow of Xiaolangd Reservoir during Water and Sediment Regulation Period of 2011 (Instantaneous)

\begin{tabular}{|c|c|c|c|c|c|}
\hline Statistical Time & $\begin{array}{l}\text { Water Inflow } \\
(0.1 \text { Billion } \\
\text { m3) }\end{array}$ & $\begin{array}{l}\text { Sediment } \\
\text { Inflow } \\
(0.1 \text { Billion } \mathrm{m} 3)\end{array}$ & $\begin{array}{l}\text { Water } \\
\text { Outflow } \\
(0.1 \text { Billion } \\
\text { m3) }\end{array}$ & $\begin{array}{l}\text { Sediment } \\
\text { Outflow } \\
(0.1 \text { Billion } \\
\text { m3) }\end{array}$ & $\begin{array}{c}\text { Sediment } \\
\text { Discharge } \\
\text { Ratio } \\
(\%)\end{array}$ \\
\hline June $19 \sim$ July 8 & 10.235 & 0.260 & 49.524 & 0.378 & 145.4 \\
\hline 5:00 July $4 \sim 8: 00$ July 8 & 5.785 & 0.260 & 6.286 & 0.378 & 145.4 \\
\hline $\begin{array}{l}\text { 18:12 July } 4 \sim 19: 12 \text { July } 5 \\
\text { (First Stage) }\end{array}$ & - & 0 & - & 0.285 & - \\
\hline $\begin{array}{l}19: 12 \text { July } 5 \sim 8: 00 \text { July } 8 \\
\text { (Second Stage) }\end{array}$ & - & 0.260 & - & 0.093 & 35.8 \\
\hline
\end{tabular}

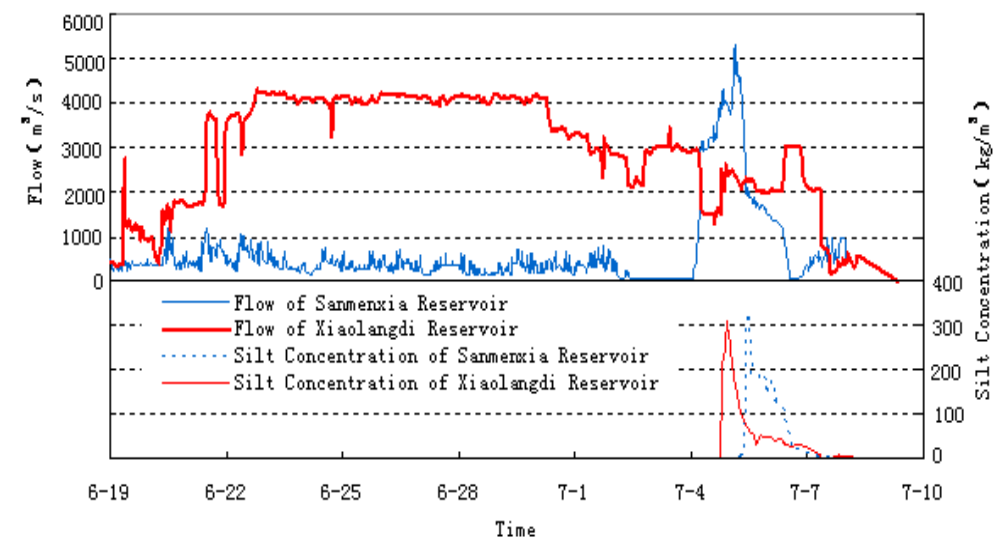

Fig. 2: Water and Sediment Inflow and Outflow Process of Xiaolangdi Reservoir (Instantaneous)

\section{Main Influencing Factors for Reservoir Sediment Discharge}

\section{Operation of Sanmenxia Reservoir}

According to analysis of water and sediment regulation before each flood season, sediment of density current of Xiaolangdi Reservoir mainly comes from erosion sediment of Xiaolangdi Reservoir delta section and erosion sediment of Sanmenxia Reservoir. The former water flow is mainly water reserve of Sanmenxia Reservoir, and the latter is mainly decided by incoming water condition of Tongguan.

According to different water flow condition, Sanmenxia Reservoir regulation can be divided into two stages including emptying period and sediment discharge period of Sanmenxia Reservoir (Fig. 3).

Emptying Period of Sanmenxia Reservoir (5:00 July 4 10:00 July 5)

This stage mainly makes good use of water reserve of Sanmenxia Reservoir to shape large flow peak process and erode sediment of Xiaolangdi Reservoir delta section and then to cause density current under proper condition.

Sanmenxia Reservoir water level was reduced to $293.98 \mathrm{~m}$ during emptying period, and water storage capacity was reduced from 0.409 billion $\mathrm{m}^{3}$ to 0.23 million $\mathrm{m}^{3}$, water outflow of Sanmenxia Reservoir was 382.5 million $\mathrm{m}^{3}$, taking up $37.4 \%$ total water outflow during water and sediment regulation period, and sediment outflow was 1.0 million tons. 
Sanmenxia Reservoir was basically under even and open channel flow state during sediment discharge period, and got erosion in Sanmenxia Reservoir. Silt concentration outflow was up to $329 \mathrm{~kg} / \mathrm{m}^{3}$ at $11: 00$ July 5 , and outflow maintained at $1,500 \mathrm{~m}^{3} / \mathrm{s}$ and formed high silt concentration water for a long duration to supply follow-up energy for continuous running of density current. Sanmenxia Reservoir water level maintained at 293.43 293.98m due to sustainable water supply of Wanjiazhai reservoir, water outflow was 135.6 million $\mathrm{m}^{3}$, taking up $13.2 \%$ total water outflow during water and sediment regulation, sediment outflow was 24.8 million tons, taking up $95.5 \%$ total sediment outflow during water and sediment regulation period of Sanmenxia Reservoir.

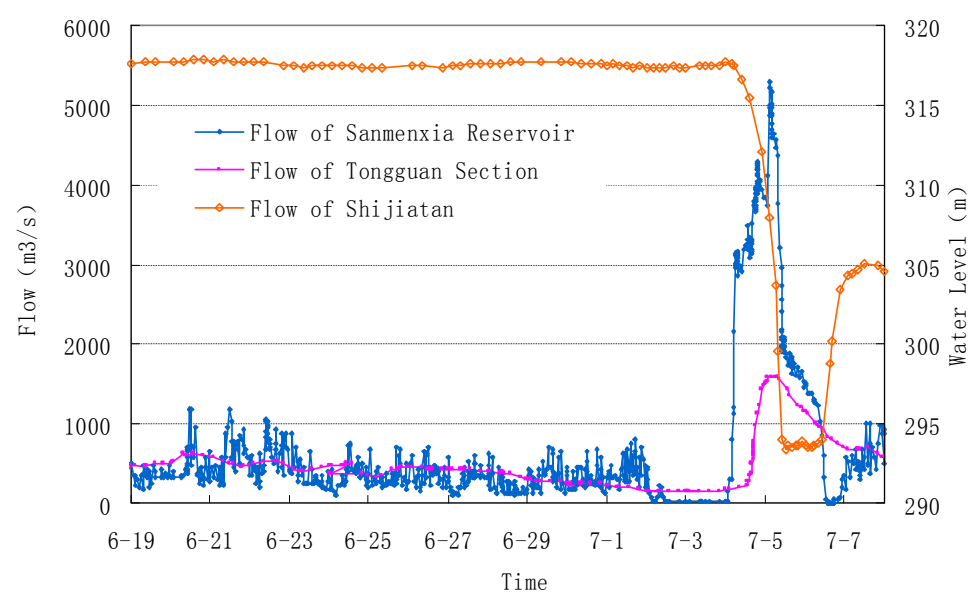

Fig. 3: Inflow, Outflow and Water Level of Sanmenxia Reservoir in 2011

It can be seen that more water storage capacity of Sanmenxia Reservoir makes greater peak flow, greater flow of Tongguan Section, longer duration and better sediment discharge efficiency.

\section{Analysis of Xiaolangdi Reservoir Application and Boundary Condition}

Xiaolangdi Reservoir kept delta sedimentation state in 2011, delta vertex forwarded from $24.43 \mathrm{~km}$ between HH15 Section of 2010 and the dam to $18.75 \mathrm{~km}$ between HH12 Section of 2011 to the dam, delta vertex elevation was reduced to $214.34 \mathrm{~m}$, delta vertex section (lower than HH37) gradient maintained $3 \%$, which was basically the same as $5.5 \% \sim 29.3 \%$ density current running reservoir bottom gradient; We can see from Fig. 4, density current running distance was $12.9 \mathrm{~km}$ in 2011 and was good for running to the front of the dam with the same power.

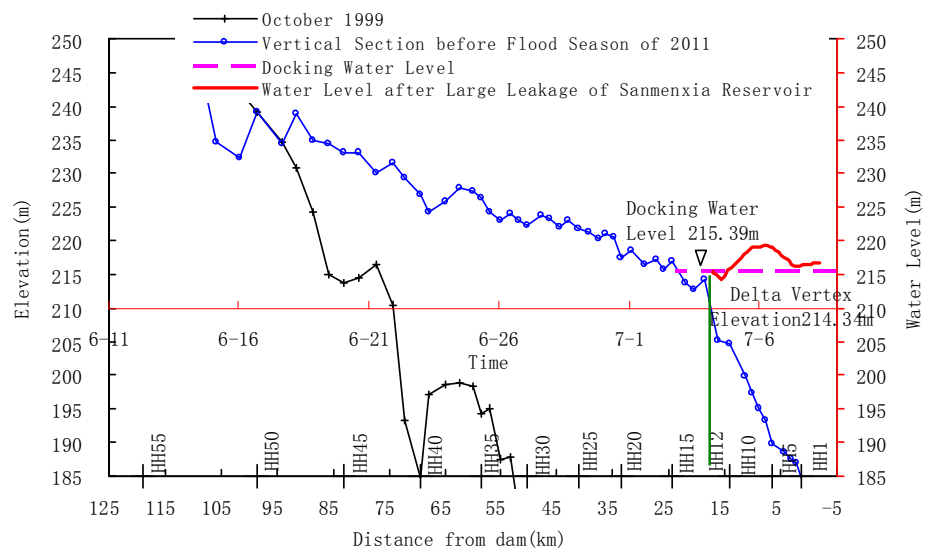

Fig. 4: Vertical Section before Flood Season of 2011 and Reservoir Water Level during Density Current Shaping Period

Large leakage of Sanmenxia Reservoir was considered as the start of shaping density current before flood season, and corresponding water level was called as docking water level. Docking water level was $215.39 \mathrm{~m}$ in 2011 and higher than delta vertex elevation $214.34 \mathrm{~m}$ but far lower than balance water depth. Water level in retrogressive erosion stage was reduced to $214.28 \mathrm{~m}$, and the section upper than plunging point occurred strong longitudinal erosion and retrogressive erosion. 


\section{Impact on Fine Inflow Sediment Concentration of Xiaolangdi Reservoir}

Density current is a kind of over saturation sediment transport, with running of density current, coarse sediment gets longitudinal sedimentation. Seen from density current sediment discharge data of Xiaolangdi Reservoir (Table 2), most sediment outflow are coarse sediment. Fine sediment content was up to over $83.94 \%$ in the years without retrogressive erosion in delta (2005 2007 and 2009); fine sediment content was still up to over $64.29 \%$ in the years with retrogressive erosion in delta like 2008, 2010 and 2011.

Seen from fine sediment inflow content statistics of Xiaolangdi Reservoir during density current shaping period before flood season, fine sediment took up $43.04 \%$ total sediment in 2006 , and sediment discharge ratio was up to $30 \%$ even under poor density current shaping condition; while fine sediment took up $27.16 \%$ only in 2009 , which was one reason for lower sediment discharge ratio in 2009. Fine sediment was $41.90 \%$ in 2011 , and sediment discharge ratio was $145.38 \%$ in 2011 , higher than $137.02 \%$ in 2010 , as the maximum ratio in water and sediment regulation statistics. Thus, we can see that higher fine sediment inflow content can make higher sediment discharge ratio of density current during density current shaping period.

Table 2-1: Fine Sediment Outflow Content of Xiaolangdi Reservoir

\begin{tabular}{ccccc}
\multicolumn{4}{c}{ Table 2-1: Fine Sediment Outflow Content of Xiaolangdi Reservoir } \\
\hline & Duration & \multicolumn{2}{c}{$\begin{array}{c}\text { Sediment Volume } \\
(0.1 \text { Billion Tons) }\end{array}$} & $\begin{array}{c}\text { Sediment } \\
\text { Discharge } \\
\text { Ratio }\end{array}$ \\
\cline { 2 - 5 } & (Month.Day) & Sanmenxia & Xiaolangdi & $(\%)$ \\
\hline In 2004 & $7.7 \sim 7.14$ & 0.385 & 0.055 & 14.29 \\
In 2005 & $6.27 \sim 7.2$ & 0.452 & 0.02 & 4.42 \\
In 2006 & $6.25 \sim 6.29$ & 0.23 & 0.069 & 30 \\
In 2007 & $6.26 \sim 7.2$ & 0.613 & 0.234 & 38.17 \\
In 2008 & $6.27 \sim 7.3$ & 0.741 & 0.458 & 61.81 \\
In 2009 & $6.30 \sim 7.3$ & 0.545 & 0.036 & 6.61 \\
In 2010 & $7.4 \sim 7.7$ & 0.408 & 0.559 & 137.02 \\
In 2011 & $7.4 \sim 7.7$ & 0.26 & 0.378 & 145.38 \\
In 2012 & $7.2 \sim 7.12$ & 0.448 & 0.576 & 128.80 \\
In 2013 & $7.2 \sim 7.9$ & 0.377 & 0.632 & 167.54 \\
In 2014 & $6.29-7.9$ & 0.636 & 0.269 & 42.3 \\
\hline
\end{tabular}

Table2-2: Fine Sediment Outflow Content of Xiaolangdi Reservoir

\begin{tabular}{|c|c|c|c|c|}
\hline Year & $\begin{array}{l}\text { Fine Sediment Inflow } \\
\text { (0.1 Billion Tons })\end{array}$ & $\begin{array}{c}\text { Fine Sediment } \\
\text { Outflow }(0.1 \text { Billion } \\
\text { Tons })\end{array}$ & $\begin{array}{l}\text { Percent of Fine } \\
\text { Sediment Inflow in } \\
\text { Total Sediment } \\
\text { Volume (5) }\end{array}$ & $\begin{array}{c}\text { Percent of Fine } \\
\text { Sediment Outflow in } \\
\text { Total Sediment } \\
\text { Volume (5) }\end{array}$ \\
\hline In 2004 & 0.133 & 0.047 & 34.55 & 86.13 \\
\hline In 2005 & 0.167 & 0.018 & 36.95 & 90.97 \\
\hline In 2006 & 0.099 & 0.059 & 43.04 & 85.4 \\
\hline In 2007 & 0.246 & 0.196 & 40.13 & 83.94 \\
\hline In 2008 & 0.239 & 0.361 & 32.25 & 78.78 \\
\hline In 2009 & 0.148 & 0.032 & 27.16 & 88.87 \\
\hline In 2010 & 0.141 & 0.359 & 34.52 & 64.29 \\
\hline In 2011 & 0.109 & 0.254 & 41.9 & 67.28 \\
\hline In 2012 & 0.142 & 0.296 & 31.7 & 51.4 \\
\hline In 2013 & 0.149 & 0.419 & 39.4 & 66.3 \\
\hline In 2014 & 0.174 & 0.218 & 27.4 & 80.9 \\
\hline
\end{tabular}




\section{Conclusion}

Based on the above analysis, this paper has brought up the main reasons for sediment discharge ratio during water and sediment regulation period before flood season as follows:

Water storage capacity before flood season and large clean water discharging process of Sanmenxia Reservoir have key impact on shaping density current forward and sediment discharge of the Reservoir. Sanmenxia Reservoir shall store water as much as possible before flood season and gradually enlarge water outflow before discharge. It is the mature experience that shall be kept on.

Xiaolangdi Reservoir upper than the backward end occurs retrogressive erosion and longitudinal erosion which can greatly increase silt concentration at plunging point of density current when docking water level is close to or is lower than the sedimentation delta vertex elevation of Xiaolangdi Reservoir and is combined with large flow discharging process of Sanmenxia Reservoir. Xiaolangdi Reservoir sediment outflow that is led in large clean water discharging process during water and sediment regulation period of Sanmenxia Reservoir before flood season of 2011 takes up $75.4 \%$ total sediment discharge volume, which fully indicates that the regulation can improve sediment discharge efficiency of erosion-type density current.

Water and sediment process of Tongguan Section takes great impact on shaping density current. Longer duration of more than $1,000 \mathrm{~m}^{3} / \mathrm{s}$ Tongguan water inflow makes higher water level of Sanmenxia Reservoir during large clean water discharging period of Sanmenxia Reservoir and particularly the emptying and sediment discharging period, Xiaolangdi Reservoir forms stronger follow-up power of density current and makes erosion or reduced siltation at the end of Xiaolangdi Reservoir under the condition of better water and sediment proportion.

Siltation delta vertex of Xiaolangdi Reservoir is near to the dam, delta vertex gets more fine siltation before flood season and topography condition at the end of Xiaolangdi Reservoir is good enough (more siltation and great gradient before flood season), all of these factors are good for increasing sediment discharge efficiency of reservoir density current.

\section{Acknowledgements}

The research was supported by public welfare industry research special fund of the Ministry of Water Resources (MWR) (No. 201401023,201501003, 201501033), the National Natural Science Foundation of China(NSFC)(No.51179072,51309110)an d central-level nonprofit research institute fund (HKY-JBYW-2014-10).

\section{References}

[1] Li Shuxia, Zhang Junhua, Chen Shukui, et al. Studies on key technologies and regulation schemes of density current forming in Xiaolangdi Reservoir [J]. Journal of Hydraulic Engineering, 2006(5): 567-572. (In Chinese)

[2]. The analysis and calculation on erosion-deposition and effective storage of Xiaolangdi Reservoir area [R]. Reconnaissance,Planning, Design and Research Institute of Yellow River Conservancy Commission. September, 1983. (In Chinese)

[3] River Channel Laboratory of Institute for Hydraulic Engineering of Shaanxi Province, Sediment Research Laboratory of the Department of Hydraulic Engineering of Tsing Hua University [M]. Reservoir Sediment. Beijing: Hydraulic and Electric Power Press, 1979: 125-128. (In Chinese)

[4] Zhang Qishun and Zhang Zhenqiu. The calculations on reservoir scouring and silting patterns and processes [J]. Sediment Research, 1982(1):1-13.

[5] Han Qiwei. Reservoir Sedimentation [M]. Science Press, August 2003: 97-100. (In Chinese)

[6] Ma Huaibo, Zhang Junhua, Chen Shukui, et al. A scheme design of sediment discharging by density current of Xiaolangdi Reservoir during water and sediment regulation before flood season in 2005 [A]. 
International Forum on Energy, Environment Science and Materials (IFEESM 2015)

Proceedings of the 6th National Sediment Basic. Theory Research Academic Symposium [C]. November 2005: 1028-1034. (In Chinese) 